\title{
Determinants of enrolment and experiences of Rashtriya Swasthya Bima Yojana (RSBY) beneficiaries in Udupi district, India
}

\section{Ramachandra Kamath, Noore Sanah, Leonard M. Machado, Varalakshmi Chandra Sekaran}

Department of Public Health, Manipal University, Manipal, Bengaluru, Karnataka, India

Address for the Correspondence: Dr. Varalakshmi Chandra Sekaran, Department of Public Health, Manipal University, Madhav Nagar, Manipal - 576104

Karnataka, India.

E-mail: drvaralakshmic@gmail.com

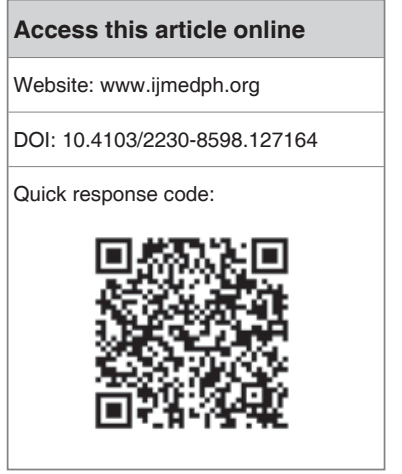

Background: Morbidities have emerged as major threats to livelihoods of the poor. An estimated 150 million have been reported as spending more than $40 \%$ of their income on their health needs. Aim: To identify the determinants of enrolment and experiences of Rashtriya Swasthya Bima Yojana (RSBY) beneficiaries in Udupi district, India. Materials and Methods: A cross-sectional study was carried out in Udupi district between March and August 2012. A mixed method approach using qualitative and quantitative methods was used. The study included all households who were eligible under the RSBY scheme recognized by the Planning Commission of India as below poverty line (BPL) households and participants recruited above 18 years of age. The sample included in the study was 316 households and took into account $95 \%$ confidence interval and $20 \%$ precision. Results: Education of the household head, marital status, household size and awareness of the cost of enrollment to RSBY were seen to be significantly associated with enrollment to RSBY $(P<0.05)$. Logistic regression analysis of four variables which showed statistical significance including household size, marital status, education, and prior awareness about the cost of enrollment into RSBY showed that prior knowledge of the cost of enrollment into the scheme and household size of less than five were major determinants to enrolling for RSBY. On qualitative analysis, the majority of the scheme users reported that the enrolment under RSBY had benefitted them and they are willing to renew the scheme again in the next round of enrollment. Conclusions: The awareness on scheme details among those included in the present study was found to be low. Information and education campaigns could improve involvement of both the insurers as well as the local institutions offering care and possibly increase utilization rate of RSBY.

Key words: Health insurance, India, RSBY

\section{INTRODUCTION}

Morbidities have emerged as major threats to livelihoods of the poor, and increasingly preserving the health of the community is proving to be a worthy investment. In the context of the developing world, the underprivileged have had to bear the brunt of rising medical expenditures with ill health robbing them of household incomes. An estimated 150 million have been reported as spending more than $40 \%$ of their income on their health needs, which could contribute to the vicious cycle of poverty perpetuating poverty. ${ }^{[1]}$ The report of the National Commission on Macroeconomics and Health, 2005, reveals that three-fourths of all health expenditure in India is by the households ${ }^{[2]}$ which is substantiated by a report by the World Health Organization (WHO) which states that private expenditure on health in 2006 was $75 \%$ compared to the $25 \%$ expenditure by general government spending. ${ }^{[3]}$ By estimates of the National Sample Survey Office (NSSO), 2004, in India, poverty is propagated due to sickness and $1 \%$ of the poor are estimated to fall below the poverty line tending to their illness and an estimated $65 \%$ of the poor in India get further into debt because of this very reason.

Following in the footsteps of successful models of health insurance instituted in other nations, the Government of India introduced the Rashtriya Swasthya Bima Yojana (RSBY) on $1^{\text {st }}$ April $2008 \cdot \cdot^{[4]}$ 
This national health insurance scheme aims at providing health insurance to households living below poverty line (BPL) in order to protect them from major health shocks that involve hospitalization up to INR $30,000 .^{[4]}$

This scheme covers several aspects of medical care including medication expenses, food and shelter involved during hospitalization, all of which are covered within the package rates and paid by the insurance companies to the hospital. The beneficiary, however, has to pay for the 'smart card' which is a nominal fee of about INR 30. This card enables the beneficiary to use the facilities provided in any network hospital in any part of the country which was instituted keeping in mind the migrant workers in the nation. ${ }^{[5]}$ This initiative has garnered international response with the World Bank stating that it is "one of the most promising efforts in India" and "a model of good design and implementation with important lessons for other programs in India". ${ }^{[6]}$

The RSBY scheme has been initiated in 25 states in India with three states yet to be a participant in the scheme. ${ }^{[4]}$ The rate of enrollment varies in different parts of India with Udupi district in Karnataka has registered RSBY scheme enrollment rate of $49 \%{ }^{[7]}$

By early 2012, the total number of households enrolled in Karnataka is 1,680,913 of the 3,671,204 eligible BPL families. As of March 2013, the number of eligible families in Udupi district for enrollment under the RSBY scheme is 43,668; while the number enrolled is 21,574. Empanelled hospitals are 20 with 17 private and three public hospitals. The number of hospitalizations so far is 2,357 with a hospitalization value of INR 12,117,225.00.[7]

The current study intended to explore various factors that influence people's decision to join or the barriers to enrollment in the scheme. The objective of this study was to identify the determinants to enrollment in the RSBY scheme in Udupi district.

\section{MATERIALS AND METHODS}

Due clearance from the ethical committee was obtained before carrying out the study. A mixed method approach (both qualitative and quantitative research methods) was used in the study. The study was carried out in Udupi district targeting the three constituent taluks including, Udupi, Kundapura, and Karkala taluks. The district is located at the southern coastal belt of Karnataka state having a population of $1,177,908$. Males constituted $47.8 \%(562,896)$ of the population and $52.2 \%(1,112,243)$ were females.

The study included all households who were eligible under the RSBY scheme recognized by the Planning Commission of India as BPL households and interviewed participants above 18 years of age. The sample size was calculated by using comparison of two proportions. Adjusting for design effect and nonresponse (20\%), the minimum sample size that was required for this study was estimated as 316 households. This sample size took into account 95\% confidence interval and $20 \%$ precision.
To achieve the second objective, a convenient sample of 20 RSBY users was selected randomly across the district.

Two stage cluster sampling technique was adopted. The selection of households was carried out including both enrolled and non-enrolled households which were selected randomly.

The quantitative method includes household interviews with enrolled and non-enrolled households to identify determinants of enrollment in RSBY scheme. The qualitative methods includes in-depth interviews with the RSBY hospitalized households to know the experiences of those who availed the benefits of RSBY and to explore whether out of pocket expenses are still incurred by the patients utilizing this scheme. A total of 336 households (316 households for quantitative and 20 households for qualitative) were recruited for the study.

Pretesting of the tools used was done on 10 households in Hiriadka Panchayth of Udupi taluk to validate the tool and ensure reliability. The tool was translated into the local language (Kannada) and then the refined version was used in the final study.

A. Interview schedule was used to collect data on determinants of enrollment comprising of the sociodemographic details of the head of the household and other variables.

B. In-depth interview guide was used to record the experiences of the RSBY scheme users.

Quantitative analysis was done using Statistical Package for Social Sciences (SPSS) version 15. The data is summarized in the form of tables showing descriptive statistics for each variable. Chi-square test and logistic regression analysis was used to assess for statistically significant associations.

Qualitative analysis was done using a framework approach. The interview responses were read thoroughly and looked for the patterns or themes among the participants. The data was transcribed and analyzed.

\section{RESULTS}

Table 1 depicts the demographic determinants of enrollment into the RSBY scheme. Of the eligible households sampled, the majority were headed by men (enrolled $=70.9 \%$, non-enrolled $=68.4 \%$ ). Most (enrolled $=84.2 \%$, non-enrolled $=72.2 \%$ ) respondents were married and ascribed to the Hindu religion (enrolled $=86.7 \%$ and non-enrolled $=89.2 \%$ ). Table 2 depicts the socioeconomic determinants of enrollment into the RSBY scheme. A larger majority belonged to the other backward class (OBC) (enrolled $=73.4 \%$ and non-enrolled $=79.7 \%$ ) and the major family type was nuclear (enrolled $=77.2 \%$, non-enrolled $=82.3 \%$ ).

The majority of participants admitted to having completed primary education (enrolled $=45.6 \%$ and non-enrolled $=56.3 \%$ ). Daily wages work was the most common occupation among both groups (enrolled $=75.9 \%$ and non-enrolled $=77.8 \%$ ) with the larger majority earning between INR 5,000-10,000. Distance required to travel for enrollment into the scheme was reported by the majority 


\begin{tabular}{|c|c|c|c|c|c|}
\hline Determinants & $\begin{array}{c}\text { Enrollee } \\
N(\%)\end{array}$ & $\begin{array}{c}\text { Non-enrollee } \\
N(\%)\end{array}$ & $\begin{array}{l}\text { Total } \\
N(\%)\end{array}$ & $\chi^{2}$ value & $P$-value \\
\hline HH head_Age & & & & 3.125 & 0.373 \\
\hline Less than 30 & $23(14.6)$ & $14(8.9)$ & $37(11.7)$ & & \\
\hline $31-40$ & $51(32.3)$ & $49(31)$ & $100(31.6)$ & & \\
\hline $41-60$ & $72(45.6)$ & $79(50)$ & $151(47.8)$ & & \\
\hline More than 61 & $12(7.6)$ & $16(10.1)$ & $28(8.9)$ & & \\
\hline Total & $158(100)$ & $158(100)$ & $316(100)$ & & \\
\hline HH head_Gender & & & & .239 & 0.625 \\
\hline Male & $112(70.9)$ & $108(68.4)$ & $220(69.6)$ & & \\
\hline Female & $46(29.1)$ & $50(31.6)$ & $96(30.4)$ & & \\
\hline Total & $158(100)$ & $158(100)$ & $316(100)$ & & \\
\hline HH head_Marital status & & & & 8.043 & 0.018 \\
\hline Single & $14(8.9)$ & $18(11.4)$ & $32(10.1)$ & & \\
\hline Married & $133(84.2)$ & $114(72.2)$ & $247(78.2)$ & & \\
\hline Widowed & $11(7)$ & $26(16.5)$ & $37(11.7)$ & & \\
\hline Total & $158(100)$ & $158(100)$ & $316(100)$ & & \\
\hline Type of family & & & & 2.185 & 0.335 \\
\hline Nuclear & $122(77.2)$ & $130(82.3)$ & $252(79.7)$ & & \\
\hline Joint & $26(16.5)$ & $17(10.8)$ & $43(13.6)$ & & \\
\hline Extended & $10(6.3)$ & $11(7)$ & $21(6.6)$ & & \\
\hline Total & $158(100)$ & $158(100)$ & $316(100)$ & & \\
\hline Household size & & & & 7.966 & 0.005 \\
\hline Less than 5 & $90(57)$ & $114(72.2)$ & 204 (64.6) & & \\
\hline More than 5 & $68(43)$ & $44(27.8)$ & $112(35.4)$ & & \\
\hline Total & $158(100)$ & $158(100)$ & $316(100)$ & & \\
\hline
\end{tabular}

(enrolled $=47.5 \%$ and non-enrolled $=46.2 \%$ ) to be between 2 and $5 \mathrm{~km}$ from their residence. Table 3 depicts the scheme cost as a determinant to enrollment to the RSBY scheme. Among those who did not enroll into the RSBY scheme, 31.6\% reported being unaware of the scheme itself and $32.3 \%$ did not know the cost of enrolling into RSBY.

Education of the household head, marital status, household size, and awareness of the cost of enrollment to RSBY were seen to be significantly associated with enrollment to RSBY $(P<0.05)$.

Table 4 depicts the logistic regression analysis. Logistic regression analysis of four variables which showed statistical significance with chi-square test including household size, marital status, education, and prior awareness about the cost of enrollment into RSBY showed that prior knowledge of the cost of enrollment into the scheme and household size of less than five were major determinants to enrolling for RSBY.

Qualitative analysis of patient experience among RSBY beneficiaries was done. The profile of RSBY beneficiaries showed that the majority were in the age group of 55-64 years. Males and females were equally distributed. Three-fourths of those interviewed ascribed to the Hindu religion. Most of them lived in nuclear families and were married. Almost all the beneficiaries had education of less than primary school while six were illiterate. Daily wages workers predominated followed by housewives. About half of the users had a monthly family income between INR 5,000 and 10,000.
Majority of the scheme users had undergone some form of surgery under the RSBY scheme. All of the hospitalized scheme users reported that they had used the scheme in private health facilities. Major reasons to opt for private health facility for hospitalization was as they were nearby followed by network hospitals as mentioned in the pamphlet given to the enrollees and because of the provision of specialty care in certain hospitals. Most of those hospitalized reported inpatient hospitalization of more than 1 week with health care expenditure of more than INR 5,000. Sources of healthcare expenditure were cited as partially from the RSBY scheme and partially from household savings.

With regard to inpatient experiences, the majority of the beneficiaries reported that a separate RSBY helpdesk was available at each health facility. All patients completed their fingerprint verification before the treatment for availing the facility. However, one common issue emerged that the beneficiaries were not informed of the projected length of their hospital stay and the cost of treatment. When asked about out of pocket expenditure incurred during hospital stay, most of them reported to have spent their own savings or having borrowed from friends or relatives to cover expenses of food, medicines, and transportation. Only a few people reported that transportation allowance was paid to them under RSBY scheme. Almost all of the patients reported that their health had improved as an outcome of using hospitalization services. Only one patient reported that the health status had worsened. However, majority of the scheme users reported that the enrolment under RSBY had 


\begin{tabular}{|c|c|c|c|c|c|}
\hline Determinants & $\begin{array}{c}\text { Enrollee } \\
N(\%)\end{array}$ & $\begin{array}{c}\text { Non-enrollee } \\
N(\%)\end{array}$ & $\begin{array}{l}\text { Total } \\
N(\%)\end{array}$ & $\chi^{2}$ value & $P$-value \\
\hline Religion & & & & 1.076 & 0.662 \\
\hline Hindu & $137(86.7)$ & $141(89.2)$ & $278(88)$ & & \\
\hline Muslim & $19(12)$ & $14(8.9)$ & $33(10.4)$ & & \\
\hline Christian & $2(1.3)$ & $3(1.9)$ & $5(1.6)$ & & \\
\hline Total & $158(100)$ & $158(100)$ & $316(100)$ & & \\
\hline Social group & & & & 4.203 & 0.243 \\
\hline Scheduled caste (SC) & $33(20.9)$ & $23(14.6)$ & $56(17.2)$ & & \\
\hline Scheduled tribe (ST) & $7(4.4)$ & $4(2.5)$ & $11(3.5)$ & & \\
\hline Other backward class (OBC) & $116(73.4)$ & $126(79.7)$ & $242(76.6)$ & & \\
\hline Others & $2(1.3)$ & $5(3.2)$ & $7(2.2)$ & & \\
\hline Total & $158(100)$ & $158(100)$ & $316(100)$ & & \\
\hline Education_HH_Head & & & & 7.931 & 0.047 \\
\hline Illiterate & $38(24.1)$ & $33(20.9)$ & $71(22.5)$ & & \\
\hline Primary $\left(1-7^{\text {th }}\right)$ & $72(45.6)$ & $89(56.3)$ & $161(50.9)$ & & \\
\hline Secondary $\left(8-10^{\text {th }}\right)$ & $42(26.6)$ & $25(15.8)$ & $67(21.2)$ & & \\
\hline Above secondary $(12+)$ & $6(3.8)$ & $11(7)$ & $17(5.4)$ & & \\
\hline Total & $158(100)$ & $158(100)$ & $316(100)$ & & \\
\hline Occupation_HH_head & & & & 0.752 & 0.687 \\
\hline Regular salaried job & $14(8.9)$ & $16(10.1)$ & $30(9.5)$ & & \\
\hline Daily wage worker & $120(75.9)$ & $123(77.8)$ & $243(76.9)$ & & \\
\hline Self-employed & $24(15.2)$ & $19(12)$ & $43(13.6)$ & & \\
\hline Total & $158(100)$ & $158(100)$ & $316(100)$ & & \\
\hline Monthly household income (Rs.) & & & & 0.484 & 0.785 \\
\hline Less than 5,000 & $53(33.5)$ & $50(31.6)$ & $103(32.6)$ & & \\
\hline $5,000-10,000$ & $57(36.1)$ & $63(39.9)$ & $120(38)$ & & \\
\hline More than 10,000 & $48(30.4)$ & $45(28.5)$ & $93(29.4)$ & & \\
\hline Total & $158(100)$ & $158(100)$ & $316(100)$ & & \\
\hline
\end{tabular}

\begin{tabular}{|c|c|c|c|c|c|}
\hline Determinant & $\begin{array}{c}\text { Enrollee } \\
N(\%)\end{array}$ & $\begin{array}{c}\text { Non-enrollee } \\
N(\%)\end{array}$ & $\begin{array}{l}\text { Total } \\
N(\%)\end{array}$ & $\chi^{2}$-value & $P$-value \\
\hline Awareness about scheme cost & & & & 62.516 & 0.001 \\
\hline Yes & $121(76.6)$ & $51(32.3)$ & $172(54.4)$ & & \\
\hline No & $37(23.4)$ & $107(67.7)$ & $144(45.6)$ & & \\
\hline Total & $158(100)$ & $158(100)$ & $316(100)$ & & \\
\hline
\end{tabular}

\begin{tabular}{|c|c|c|c|c|c|c|}
\hline Determinants & $\begin{array}{c}\text { Enrollee } \\
\qquad(\%)\end{array}$ & $\begin{array}{c}\text { Non-enrollee } \\
N(\%)\end{array}$ & $\begin{array}{l}\text { Total } \\
N(\%)\end{array}$ & $\begin{array}{l}\text { Adjusted odds } \\
\text { ratio }\end{array}$ & $P$-value & $\begin{array}{c}95 \% \text { confidence } \\
\text { interval }\end{array}$ \\
\hline \multicolumn{7}{|l|}{ Education of the head } \\
\hline Illiterate & $38(24.1)$ & $33(20.9)$ & $71(22.5)$ & 1 & & \\
\hline Primary & $72(45.6)$ & $89(56.3)$ & $161(50.9)$ & 1.61 & 0.157 & $(0.832-3.106)$ \\
\hline Secondary above and & $48(30.4)$ & $36(22.8)$ & $84(26.6)$ & 1.12 & 0.779 & $(0.520-2.390)$ \\
\hline \multicolumn{7}{|c|}{ Marital status of the head } \\
\hline Single & $14(8.9)$ & $18(11.4)$ & $32(10.1)$ & 1 & & \\
\hline Married & $133(84.2)$ & $114(72.2)$ & $247(78.2)$ & 0.84 & 0.684 & $(0.353-1.981)$ \\
\hline Widowed & $11(7)$ & $26(16.5)$ & $37(11.7)$ & 1.77 & 0.338 & $(0.549-5.737)$ \\
\hline \multicolumn{7}{|c|}{ Prior awareness of scheme cost } \\
\hline No & $37(23.4)$ & $107(67.7)$ & $144(45.6)$ & 1 & & \\
\hline Yes & $121(76.6)$ & $51(32.3)$ & $172(54.4)$ & 0.16 & 0.001 & $(0.094-0.260)$ \\
\hline \multicolumn{7}{|l|}{ Household size } \\
\hline More than 5 & $68(43)$ & $44(27.8)$ & $112(35.4)$ & 1 & & \\
\hline Less than 5 & $90(57)$ & $114(72.2)$ & $204(64.6)$ & 1.77 & 0.038 & $(1.031-3.034)$ \\
\hline
\end{tabular}


benefitted them and they are willing to renew the scheme again in the next round of enrollment.

Experiences recounted by RSBY beneficiaries included:

"RSBY scheme has come to us at the right time when we were in real need of financial aid which has helped us to utilize the benefits of healthcare and lower the burden of healthcare expenses.

I am too old to go field and work to earn money for my living. I had RSBY heath card. So, I underwent treatment in private healthcare facility or else I could have not gone to the hospital by spending my money as it is unaffordable.

I am happy that the government has launched a scheme like RSBY for BPL population like us so that we can have better access to healthcare, wherein we do not have to spend large amounts of money and in the meantime avail maximum benefits. RSBY scheme has not been helpful. Following enrollment into the scheme has not given the benefits, which we were informed of before enrollment. When we visited the network hospital which was mentioned in the pamphlet provided during the enrollment camp, the provider said that due to technical problems the RSBY smart card cannot be opened. Hence, we had to borrow money to overcome the hospitalization expenses."

\section{DISCUSSION}

Education of the head of the household, being married, household size, and awareness of the cost of subscribing to the scheme emerged as being significantly associated with enrollment into the RSBY scheme. Using logistic regressing analysis, household size of less than five and awareness of the cost of enrollment to the RSBY scheme emerged as major determinants of scheme subscription. People who were aware about the cost of enrollment which is about INR 30 were seen to be enrolled in comparison with those without prior knowledge of the cost of the scheme.

The study findings were similar to findings by several other studies. Kirigia et al., ${ }^{[8]}$ reported marital status and education as some of the major determinants of ownership of health insurance in their study population. Education and marital status also appeared to be significant factors influencing the decision to own health insurance as noted by Bourne et al. ${ }^{[9]}$ in their study while education also emerged as a major determinant among participants in enrollment into community health insurance in a study by De Allegri et al., , $^{[0]}$ and Doyle and Panda ${ }^{[11]}$ reported similar findings in their study among senior members with education playing an important role in determining use of insurance schemes.

Access to educational institutions and education of family members stood out as influencers in studies conducted across India among those enrolled in the RSBY scheme. ${ }^{[12,13]}$

Another crucial determinant to enrollment in the scheme was found to be awareness of the cost of enrollment into the RSBY scheme. Cost of enrollment to insurance schemes was also seen to be an important determinant to enrollment in prior studies by Basaza et al., ${ }^{[14]}$ and Thornton et al., ${ }^{[15]}$ Prior awareness about the cost of enrollment to RSBY emerged as a major determinant in the current study.

The success of any program depends on the utilization of the scheme and the satisfaction of the users. The qualitative findings of the study revealed that majority of the scheme users reported that the enrolment under RSBY has benefitted them and they are willing to renew the scheme again in the next round of enrollment.

\section{CONCLUSION}

The awareness on scheme related details including what enrollment entailed among those included in the present study was found to be low. The study subjects were also unaware of their network hospitals and scheme benefits. It is recommended that concurrent information and education campaign programs be conducted with the involvement of both the insurers as well as the local institutions offering care to enable the improvement in the enrolment and utilization rate. Assessment of the campaigns should also be conducted to monitor effectiveness of the campaigns in getting the word out.

Involvement of the community stakeholders within the health system such as Accredited Social Health Activists (ASHAs), Anganwadi staff, and health staff can be trained to disseminate information related to RSBY in the community. Conducting regular health camps would allow those under the BPL to be screened by physicians and if need be referred to the network hospitals.

Recommendations for the next round of enrollment include pre-enrolment awareness activities involving community stake holders such as Panchayat members, ${ }^{[16]}$ Anganwadi workers, ASHA, community-based self-help group members, and local nongovernmental organizations to spread awareness using mass media, peer-to-peer, and house-to-house visit of the volunteers where required.

Other suggestions gleaned from RSBY beneficiaries using the qualitative method included:

- $\quad$ Extending the family limit of RSBY to more than five members of the household.

- Empanel tertiary hospitals in network list of RSBY.

- Increase the maximum coverage limit above INR 30,000.

- Make sure the network hospitals under RSBY are functioning well.

Further research is recommended to identify barriers and ways to overcome them in order to benefit the poor as well as to evaluate the utilization of the scheme and the quality of services provided by the network hospitals. 


\section{Limitations}

The study had some limitations including but not limited to probable bias due to data being collected only in the rural areas of Udupi taluk and not including the urban municipality areas. Difficulties were also encountered in locating the eligible BPL households from the BPL list (2002) due to errors like inappropriate address or migrant status. There is also a possibility that some underlying determinants were not accounted for in this study.

\section{ACKNOWLEDGEMENTS}

The author would like to thank and acknowledge the faculty of the Department of Public Health; Dr. N. Devadasan, Institute of Publc Health, Bangalore; Mr. K. J. Jhonson, Department of Labour, Udupi district; and Mr. Vasudevan Guddattu, Department of Statististics, Manipal University, for the support extended.

\section{REFERENCES}

1. Tanuja PK, Sihare H. Pros and cons of micro health insurance to eradicate health problems in the Below Poverty Line (BPL) population: Empirical evidence from India. Ital J Public Health Year 2011;8.

2. Available from: www.macroscan.org [Internet]. New Delhi. 2006. Government health expenditure in India: A benchmark study. Economic research foundation. Available from: http://www.macroscan.org/anl/oct06/ pdf/Health_Expenditure.pdf [Last cited on 2013 Mar 4].

3. Available from: http://www.who.int/en/ [Internet]. WHO 2012. World Health Statistics 2009. Available from: http://www.who.int/whosis/whostat/ EN_WHS09_Table7.pdf [Last cited 2013 Mar 4].

4. Available from: http://www.rsby.gov.in/ [Internet]. 2009 RSBY - Chis Evaluation Survey 2009. Available from: http://www.rsby.gov.in/ Documents.aspx?ID=14 [Last cited 2013 Mar 4].

5. Available from: http://www.rsby.gov.in/ [Internet]. 2009 RASHTRIYA SWASTHYA BIMA YOJANA - Scheme with a difference 2011. Available from: http://www.rsby.gov.in/Documents.aspx?ID=14 [Last cited 2013 Mar 4].
6. Available from: http://www.rsby.gov.in/ [Internet]. 2009 RASHRIYA SWASTHYA BIMA YOJANA (RSBY) Some initial trends.2011. Available from: http://www.rsby.gov.in/Documents.aspx?ID=14 [?Last cited on 2013 Mar 4].

7. Available from: http://www.rsby.gov.in/ [Internet]. 2009 Karnataka Enrollment of Beneficiaries. Available from: http://www.rsby.gov.in/ statewise.aspx?state $=29$ [Last cited on 2013 Mar 4].

8. Kirigia JM, Sambo LG, Nganda B, Mwabu GM, Chatora R, Mwase T. Determinants of health insurance ownership among South African women. BMC Health Serv Res 2005;5:17.

9. Bourne PA, Kerr-Campbell MD. Determinants of self-rated private health insurance coverage in Jamaica. J Health 2010;2:541-50.

10. De Allegri M, Kouyate B, Becher H, Gbangou A, Pokhrel S, Sanon M, et al. Understanding enrolment in community health insurance in subSaharan Africa: A population-based case-control study in rural Burkina Faso. Bull World Health Organ 2006;84:852-8.

11. Doyle C, Panda P. Factors influencing uptake of micro health insurance products in rural India, Working Paper 2012.

12. Available from: http://www.rsby.gov.in/ [Internet]. 2009 RSBY utilization paper 2010. Available from: http://www.rsby.gov.in/Documents. aspx?ID=14 [Last cited on 2013 Mar 4].

13. Available from: http://www.rsby.gov.in/ [Internet]. 2009 RSBY Final Report Chhattisgarh.pdf. Available from: http://www.rsby.gov.in/Documents aspx?ID=14 [Last cited on 2013 Mar 4].

14. Basaza R, Criel B, Van der Stuyft P. Low enrollment in Ugandan Community health insurance schemes: Underlying causes and policy implications. BMC Health Serv Res 2007;7:105.

15. Thornton R, Hatt EL, Field EM, Islam M, Diaz FS, González MA Social security health insurance for the informal sector in Nicaragua: A randomised evaluation. Health Econ 2010;19 Suppl:181-206.

16. Available from: http://www.rsby.gov.in/ [Internet]. 2009 Evaluation study of Rashtriya Swasthya Bima Yojana in Shimla and Kangra districts in Himachal Pradesh. Available from: http://www.rsby.gov.in/Documents. aspx?ID=14 [Last cited on 2013 Mar 4].

How to cite this article: Kamath R, Sanah N, Machado LM, Sekaran VC. Determinants of enrolment and experiences of Rashtriya Swasthya Bima Yojana (RSBY) beneficiaries in Udupi district, India. Int J Med Public Health 2014;4:82-7.

Source of Support: Nil. Conflict of Interest: No conflict of Interest. 